\title{
Research Progress on Soil and Water Loss and Soil and Water Conservation in Karst Areas
}

\author{
Yan Sun ${ }^{1,3}$, Yiyuan Zhang ${ }^{2}$, Sigao Li ${ }^{1,3}$, Nan Zhang ${ }^{1,3}$ and Junming Wang ${ }^{1,3^{*}}$ \\ ${ }^{1}$ Guangxi Hydraulic Research Institute, Nanning, Guangxi, 530023, China \\ ${ }^{2}$ Nanning Reconnaissance \& Designing Institute of Pearl River Water Resources Commission in Guangxi, Nanning, Guangxi, 530007, \\ China \\ ${ }^{3}$ Guangxi Key Laboratory of Water Engineering Materials and Structures, Nanning, Guangxi, 530023, China
}

\begin{abstract}
Based on the research of soil erosion and soil and water conservation in karst areas in China in recent years, the status and progress of soil erosion and soil and water conservation in karst areas in China are discussed. The results show that the soil and water loss in the karst area mainly has two types of soil erosion: surface soil erosion and underground soil erosion. Soil and water loss management in karst areas mainly adopts measures to adjust land use structure, increase vegetation coverage, carry out slope-to-ladder construction, and promote clean energy applications. Different governance models should be adopted for different landform types, different landform parts, different slopes, and different levels of rocky desertification in karst areas.
\end{abstract}

\section{Foreword}

Karst is a general term for the geological effects of water on soluble rocks, which mainly include chemical dissolution, supplemented by mechanical effects such as erosion, subduction and collapse of flowing water, and the phenomena caused by these effects. The karst area has a slow soil formation rate and low vegetation coverage, which is very easy to cause soil erosion. Serious soil erosion results in surface soil loss, exposed bedrock, and even rocky desertification. The ecological environment in the karst region is extremely fragile, but there is a large number of agricultural population, with little per capita arable land, and the contradiction between man and land is prominent in the area.

As early as the 1920s, domestic and foreign scholars began to explore the research of soil erosion and soil and water conservation in karst areas. So far, the research is mainly divided into 4 stages: the 1920 s to the 1950 s is the exploration stage; the 1960s-70s was the stage of enlightenment; the 1980s-90s was the stage of slow development; from 2000 to the present, it is a stage of rapid development[1]. This article systematically summarizes the research on soil erosion and soil and water conservation in karst areas in China in recent years, presents the development trends and research priorities of research in this field during the emergence stage, and aims to provide technical support for comprehensive development of soil and water conservation work in karst areas.
Table 1. Research stages of soil and water loss and soil and water conservation in Karst Areas.

\begin{tabular}{ccc}
\hline $\begin{array}{c}\text { Serial } \\
\text { number }\end{array}$ & Period & Stage \\
\hline 1 & $1920 \mathrm{~s}-1950 \mathrm{~s}$ & Exploration \\
2 & $1960 \mathrm{~s}-1970 \mathrm{~s}$ & Enlightenment \\
3 & $1980 \mathrm{~s}-1990 \mathrm{~s}$ & Slow development \\
4 & $\begin{array}{c}\text { from 2000 to } \\
\text { the present }\end{array}$ & Rapid development \\
\hline
\end{tabular}

\section{Study on Soil and Water Loss in Karst Area}

Soil and water loss refers to the damage and loss of water and soil resources and land productivity caused by external forces such as water power, gravity, wind, and freeze-thaw and human activities. Soil and water loss in karst areas mainly includes surface water and soil loss and soil erosion in the ground.

\subsection{Surface water and soil loss}

Surface erosion mainly includes gravity erosion and hydraulic erosion. At present, the research on surface water and soil loss in karst areas has become mature, mainly using remote sensing interpretation method, runoff plot method, erosion line method, sedimentation pond method, landform observation method, 137Cs tracer and other research methods. 
Research shows that the karst area has large terrain fluctuations, steep slopes, rugged and broken surfaces, and easily generates erodable runoff. The fragility of soil ecosystems in karst areas is the internal cause of soil erosive degradation in karst mountain areas, and rapid population growth and unreasonable land development are the external forces that cause soil erosive degradation in karst areas. Because of the slow soil formation process of the carbonate rock series, the soil and water loss caused by karst areas is more harmful[2].

The current status of land use has a significant impact on soil erosion in karst areas. Compared with woodlands and shrubs, the thickness of soil layers on slope farmland is smaller, the compactness is smaller, and the soil erosion rate and soil erosion modulus are larger, soil is susceptible to erosion. When the slope coverage is increased, it has a significant control effect on soil erosion, and it is also conducive to the improvement of soil moisture.

The rate of soil erosion in the karst area varies depending on the slope position. The rate of erosion in the upper part of the slope is small, the erosion in the middle of the slope is intensified, and the erosion in the lower part of the slope is weakened or even accumulated. Cumulative mass loss and suspended mass loss on the surface generally increase with the increase of slope, and surface runoff and sediment production decrease with the increase of underground porosity[3].

\subsection{Soil erosion in the ground}

Soil erosion in the ground, or soil leakage, is a special type of soil and water loss that occurs in karst rocky desertification areas. It refers to the process by which the soil moves from the surface to the ground through dissolution fractures, karst caves, surface funnels, sinkholes, shafts, etc.. As early as the 1980s, scholars have studied the phenomenon of soil loss to underground space through lichens, spores, archeology, and soil erosion modulus.

Soluble carbonate rocks, hot and humid climate, loose and shallow soil, and fragile vegetation provide the material foundation and driving force for groundwater and soil loss in the karst area. The special double-layer structure and micro-topography also provide it with missing channels and space, and the large amount of surface precipitation seepage provides soil erosion and hydrodynamic conditions for underground leakage.

The air-dried soil aggregates disintegrate when exposed to water, and the dispersed fine-grained materials can migrate to the underground space along the pores and karst fissures between the soil. The clay filled in the karst caves is plastic, soft, and even under the infiltration and softening of flowing water, and it is flow-shaped and can be creeped and moved to the caves and underground rivers underneath, eventually leading to surface soil loss[4]. The cumulative suspended mass loss of underground hole (fracture) gap flow generally decreases with the increase of slope; underground runoff and sand production increase with the increase of underground hole (fracture) gap.
Fissures, funnels, and pores in carbonate rocks are the channels for underground migration of soil. The soil particles in the funnels and fissures are mainly silt and sand. Grain content decreases with increasing depth. The larger the volume, the smaller the amount of soil loss in the crevice and the funnel[5]. The average soil erosion modulus in karst areas is generally low, and the general criteria for dividing soil erosion intensity are not applicable to karst areas[6].

\subsection{Relationship between surface soil erosion and soil erosion in the ground}

There is a certain correlation between surface soil erosion and soil erosion in the ground. Under different conditions, the spatial distribution ratio of surface runoff and sediment production will change, significant negative correlation between surface and underground runoff.

Underground leakage can weaken surface runoff and sediment production to a certain extent. The results of artificial simulated rainfall tests show that soil and water loss under karst slopes is mainly caused by underground leakage, and even there is no sediment produced on the surface. There is a critical point of rain intensity in the spatial distribution of surface and underground runoff. The researchs are mainly through artificial simulation of the characteristics of runoff and sediment production on slopes under different rainfall intensities, underground cracks, slopes, and exposed bedrock rates. In the natural environment, due to the concealment and complexity of rock fissures which is difficult to measure, the characteristics of runoff and sediment production on the karst slope surface are more complicated.

\section{Study on Soil and Water Conservation in Karst Area}

Due to the unique hydrothermal conditions, the karst area is barren and the cultivated land is scarce. The effects of soil erosion are long-lasting and harmful. The most direct consequence is the loss of land resources and rocky desertification. Once rocky desertification occurs in the karst area, it will be very difficult to restore the land, and the speed of restoration will be very slow. Therefore, the problems of soil and water conservation in karst areas are mainly about how to prevent and control the development of rocky desertification.

\subsection{Governance measures}

The rapid population growth and unreasonable development and utilization of land are the causes and external forces leading to soil erosive degradation in karst areas. Soil and water conservation in karst areas must adhere to the principles of equal emphasis on economic and ecological benefits and sustainable development. Therefore, the soil erosion management in karst areas is mainly carried out in the following aspects: 
(1) Adjust land use structure and develop ecological agriculture. Unreasonable development and utilization of land is the main external driving force for soil erosive degradation in karst areas. Adjusting the land use structure in karst mountains, reducing land reclamation rate, rational farming, optimizing crop planting structure and layout in karst mountains, and developing ecological agriculture can fundamentally Inhibiting erosive degradation of soil in karst mountains.

(2) Increase vegetation coverage and promote local economic development. Vegetation is the key to preventing soil and water loss in karst areas. To control rocky desertification, we must adapt to local conditions and focus on the restoration of forest and grass vegetation, increase the coverage of karst land vegetation, increase the number of plant communities, and promote local economic development[7]. Specific measures include the construction of soil and water conservation forests, economic forests, and mountain closure and forestation.

(3) Transforming slope into terrace and construction of small-scale water conservancy facilities improve water resource utilization efficiency. Transforming slope into terrace appropriately can curb soil erosion on slopes. The construction of small water conservation facilities such as diversion canals, mountain ponds and pools can increase rainwater storage and improve water resource utilization efficiency. Transforming slope into terrace and construction of small-scale water conservancy facilities can improve local production and living conditions, increase the capacity of stable and high yields on sloping fields, and create conditions for returning farmland to forests.

(4) Promote the application and maintenance of clean energy and reduce the destruction of man-made vegetation. Promote the construction of biogas digesters, introduce solar energy and other facilities, promote the application and maintenance of clean energy, improve the energy structure, reduce the impact of human logging on fuelwood, and reduce the destruction of man-made vegetation[8].

\subsection{Governance model}

Soil and water conservation in karst areas must be comprehensively addressed by controlling soil erosion, preventing and controlling rocky desertification, and solving people's production and living problems. Since the 1980s, rocky desertification control has been implemented in karst areas. After years of practice, experts and scholars have formed a series of governance models suitable for karst areas based on the successful experience of practice.

(1) Governance model for different rocky desertification areas

According to different levels of rocky desertification in karst areas, scholars have proposed corresponding soil and water conservation management models: Potential rocky desertification areas use economic forest vegetation restoration sub-models; mild rocky desertification areas use comprehensive management restoration sub-models; moderate rocky desertification areas use grassland vegetation restoration sub-models; intensity rocky desertification areas use forest vegetation restoration sub-models.

(2) Governance model for different landform types

Scholars have studied the different governance models of karst areas in Guangxi, and summarized them from the local rocky desertification conditions, site conditions, governance models, and natural, economic, and social benefits. It is considered that: the compound and three-dimensional ecological agricultural governance model is suitable for the low and middle mountain clusters and depressions; the ecological migration and the mixed agricultural, forestry and animal husbandry management model is suitable for the high and middle mountain clusters and depressions; the compound and three-dimensional ecological agricultural governance model is suitable for the low and middle mountain clusters and depressions; the ecological migration and the mixed agricultural, forestry and animal husbandry management model is suitable for the high and middle mountain peaks and clusters depressions[9]; The ecological forest governance model is suitable for the peak forest Plain and karst hills[10]; the restoration of the original appearance is suitable for the three-dimensional ecological agriculture model.

(3) Governance mode for different landforms

The karst area has explored the three-dimensional ecology of the "Wuzidengke" in the practice of "planting pine and cypress at the top of the mountain, planting economic forests on the mountainside, grasping the structure adjustment under the mountain, earning money by surplus laborers, increasing income to build a beautiful rural house". The construction model makes full use of the advantages of mountain resources to achieve comprehensive management of mountains, water, forests, fields, roads, and houses.

(4) Governance model for different slopes

In practice, some karst areas have established governance models for different slopes, such as steep slopes, steep slopes, and gentle slopes, according to different slopes.

There are three modes of grass irrigation on steep slopes: water conservation forest, planting Liaoning Grass, and planting honeysuckle; modes of arbor irrigation on steep slopes include forest-medicine combination management, under-forest honeysuckle planting, bio-belt formation, forest-grass combination, forest-bamboo combination, needle-broad mixing, and fast-growing and high-yielding Lin cultivation. There are two types of forest and fruit models in gentle slopes: collective fruit management and kiwi planting.

\section{Discussion}

In recent years, domestic scholars have carried out applied research on karst rocky desertification control in karst areas such as Guizhou, Guangdong, and Guangxi, and summarized the soil and water conservation models in karst areas. The comprehensive management of soil and water loss in China's karst areas has shifted from 
focusing on curbing the expansion of rocky desertification areas and increasing the coverage of vegetation. It has shifted to the organic combination of ecological governance and ecological industries, enhanced ecological services per unit area, cultivated ecological governance derivative industries, and served the nation's ecological civilization. Although there are many types of soil and water conservation models in karst areas, soil and water conservation in karst areas is a complex systematic project. The scientificity, rationality, and applicability of some models in other areas need further study.

\section{References}

1. Yan P.,Xiong K.N.,Wang H.S.,et al. (2016)Progress of study on soil and water loss and soil and water conservation of karst region. Soil and Water Conservation in china, 2016(01):54-59+73.

2. Hu J.B. (2018) Discussion on soil erosion and ecological management in Karst area of Guizhou Province. China Resources Comprehensive Utilization, 36(02):124-125+134.

3. Fu W.B.,Dai Q.H.,Yan Y.J. (2015)The response of soil erosion in Karst slope and its shallow underground crevasse ratios. Journal of Soil and Water Conservation, 29(02):11-16+22.

4. Yue K.Q. (2016) Prevention technology demonstration of subterranean soil erosion in the typical rocky desertification area of South China karst. Guizhou Normal University,2016.

5. Lu G.Y.,Li S.,Wei X.H., et al. (2013) The processes of soil degradation in Rock Desertification area of northern Guangdong. Journal of Soil and Water Conservation, 27(02):20-25.

6. Li Y, Bai X, Zhou Y, et al. (2016)Spatial-Temporal Evolution of Soil Erosion in a Typical Mountainous Karst Basin in SW China, Based on GIS and RUSLE. Arabian Journal for Science and Engineering, 2016, 41(1):209-221.

7. Chen G.Y.(2018) Study on the Experience and Enlightenment of Comprehensive Control of Rocky Desertification in Karst Area. Journal of Green Science and Technology, 2018(16):148-149.

8. Cen Y., Yao C.P., Zhang X.Y.(2019) Discussion on Soil Erosion Distribution and Management Model of Small Watershed in Karst Region in Guangdong Based on USLE. Shaanxi Water Resources, 2019(05):117-118+123.

9. Zou Z.G., Zeng F.P. (2019)Soil and water loss and resistance control technology in karst peak-convex depression. Rural Economy and Science-Technology, 30(03):16-17.

10. Yan Y., Hu B.Q.,Hou M.F., et al. (2017)Suitability assessment of karst Rocky Desertification control patterns in karst Counties of Guangxi China. Journal of Guangxi Normal University(Natural Science Edition), 35(04):145-153. 